\title{
Current results of surgery for achalasia of the cardia
}

\author{
Ragnhild Emblem, Mark D Stringer, Christine M Hall, Lewis Spitz
}

\begin{abstract}
Several treatment options are available in the management of achalasia of the cardia. Of a recent series of 14 children, 12 were treated by a modified Heller's myotomy combined with a floppy Nissen fundoplication. Symptoms were dramatically improved in nine during a mean follow up period of 3.9 years. Recurrent oesophageal pain was the most resistant symptom and continued to be moderately severe in three patients, two of whom obtained temporary relief by oesophageal balloon dilatation. Two patients treated by pneumatic dilatation alone have residual symptoms. These results support a primary surgical approach to the management of achalasia in children.
\end{abstract}

(Arch Dis Child 1993; 68: 749-751)

Achalasia is a motility disorder of the oesophagus characterised by absence of normal peristalsis and failure of relaxation of the lower oesophageal sphincter. The condition is uncommon in children and there are few reports on the results of treatment. The therapeutic aim is to reduce the lower oesophageal sphincter pressure. In adults, pneumatic dilatation is the recommended initial treatment ${ }^{12}$ while in children, this technique has been less successful and surgery is the preferred option. ${ }^{34}$ The necessity of performing a concomitant antireflux procedure is controversial but myotomy alone is associated with a significant incidence of gastro-oesophageal reflux..$^{3-5} \mathrm{We}$ have therefore recommended a Nissen fundoplication in conjunction with a modified Heller's myotomy and previously reported four such patients. ${ }^{6}$ This report deals with the detailed symptomatic follow up of a larger number of patients treated by this method.

\section{Patients and methods}

\section{PATIENTS}

Between 1981 and 1991, 14 patients (five boys and nine girls) were referred for treatment of achalasia. Age at onset of symptoms ranged from 0.3 to 10 years with a mean of 6 years. The mean duration of symptoms before referral was $2 \cdot 2$ years (range $0 \cdot 2-5$ years) and patients have been followed up for a mean of 3.9 years (range 0.8-11 years) after treatment.

Institute of Child Health, 30 Guildford Street, Department of Paediatric Surgery

Ragnhild Emblem

Mark D Stringer

Lewis Spitz

Department of Radiology Christine M Hall

Correspondence to: Mr Stringer.

Accepted 14 January 1993

\section{PRESENTING SYMPTOMS}

Patients were graded according to a modified Vantrappen et al symptom scale': $1=$ excellent: asymptomatic, $2=$ good: symptoms less than once a week, $3=$ moderate: symptoms more than once a week, and $4=$ poor: daily symptoms. The main symptoms at presentation were dysphagia, vomiting, pain, and respiratory problems (table 1). The latter included nocturnal coughing and recurrent chest infections; four children had been diagnosed as asthmatic. Weight loss had occurred in 13 patients; all were below the 10th centile for weight and 10 were below the 3rd centile. Two girls, aged 10 and 13 years at presentation, had been diagnosed as having anorexia nervosa. One boy had adrenal glucocorticoid deficiency and deficient tear production. $^{7}$

\section{INVESTIGATIONS}

Barium swallow was diagnostic in all patients, demonstrating the typical features of achalasia: dilated body of oesophagus, absence of normal peristalsis, tertiary contractions, and the typical narrowing at the oesophagogastric junction (figure). Manometry was performed in six patients and revealed a high pressure lower oesophageal sphincter with incomplete relaxation upon swallowing. Upper gastrointestinal endoscopy was performed in all patients and showed no evidence of oesophagitis or stricture.

\section{TREATMENT}

\section{Non-operative}

Four children were initially treated with nifedipine, 5-10 mg administered before meals. Oesophageal dilatations were performed as initial treatment in seven children: $2-5$ bougie dilatations in three patients, and 1-2 forceful pneumatic balloon dilatations in four patients. Five children had postoperative dilatations: 1-5 bougie dilatations in two and 1-2 balloon dilatations of the cardia in three patients.

\section{Operative}

One patient was referred after having undergone a simple myotomy through a left thoracic approach and was treated with a Nissen fundoplication for gastro-oesophageal reflux combined with a further myotomy. In 11 other patients a modified Heller's myotomy with a Nissen fundoplication was performed via an upper abdominal midline incision. ${ }^{6}$ Myotomy comprised the removal of a longitudinal muscle strip extending from $5-7 \mathrm{~cm}$ above the cardia to $1-2 \mathrm{~cm}$ on to the gastric fundus, exposing about $50 \%$ of the oesophageal circumference at submucosal level. A short (1.5-2 cm) 'floppy' two layer Nissen fundo-

$\frac{\text { Table } 1 \text { Presenting symptoms in } 14 \text { children with achalasia }}{\text { Vantrappen et al grade }}$

\begin{tabular}{lccccc}
\hline & \multicolumn{9}{c}{ Vantrappen et al grade } & Grade 3 \\
\cline { 2 - 5 } Symptom & 4 & 3 & 2 & 1 & and 4 (\%) \\
\hline Dysphagia & 13 & 1 & - & - & $(100)$ \\
Vomiting & 12 & 1 & 1 & - & $(93)$ \\
Pain & 6 & 4 & 2 & 2 & $(71)$ \\
Respiratory problems & 6 & 2 & 2 & 4 & $(57)$
\end{tabular}


plication was then performed. Histological examination of the muscle strip was carried out in 10 patients and combined with histochemical studies in some.

\section{Results}

NON-OPERATIVE TREATMENT

Two patients reported no benefit from nifedipine treatment and in the other two there was a definite but short lived improvement in symptoms. Oesophageal dilatations were of no benefit in five of seven patients, three with bougienage and two with balloon dilatation, and all five underwent surgery. Two children were treated with forceful pneumatic balloon dilatations alone. One 6 month old infant's dysphagia was relieved but she requires medical treatment for subsequent symptomatic gastro-oesophageal reflux. The other girl, aged 6 years, has had two dilatations with only transient benefit but her parents have been reluctant for her to undergo surgery. Pneumatic balloon dilatations temporarily relieved recurrent oesophageal pain in two patients after surgery.

\section{OPERATIVE TREATMENT}

In nine patients, symptoms were dramatically relieved by surgery (table 2 ). The other three patients' symptoms were improved but they continued to suffer pain; none had evidence of gastro-oesophageal reflux on endoscopy or barium studies. All patients were cured of dysphagia and respiratory symptoms and gained weight after surgery; nine patients were above the 10th centile when last weighed. Only one patient suffered from symptomatic gas bloat, which was temporary. The patient who initially underwent a myotomy via a thoracic approach and then required a fundoplication and further myotomy, continued to suffer from recurrent severe retrosternal pain, vomiting, and weight loss. Repeat studies with oesophageal manometry demonstrated high pressure waves in the mid and lower oesophagus but a reduced lower oesophageal sphincter pressure. A barium swallow showed severe oesophageal dysmotility with tertiary contractions. Oesophageal dilatations and antispasmodic medication were unhelpful and she finally underwent a successful gastric transposition, leading to an improvement in her symptoms. ${ }^{8}$ Histology of the resected oesophagus revealed an absence of ganglion cells from the entire specimen.

Of the 12 surgically treated patients, there were no postoperative complications in eight. One girl required treatment for a left lower lobe collapse and two patients needed endoscopic removal of a food bolus in the early postoperative

Table 2 Surgical results in 12 children with achalasia

\begin{tabular}{|c|c|c|c|c|c|}
\hline \multirow[b]{2}{*}{ Symptom } & \multicolumn{4}{|c|}{ Vantrappen et al grade } & \multirow{2}{*}{$\begin{array}{l}\text { Grade } 3 \\
\text { and 4(\%) }\end{array}$} \\
\hline & 4 & 3 & 2 & 1 & \\
\hline Dysphagia & - & - & 2 & 10 & $(100)$ \\
\hline Vomiting & - & 1 & - & 11 & (92) \\
\hline Pain & 1 & 2 & 3 & 6 & $(75)$ \\
\hline Respiratory problems & - & - & - & 12 & $(100)$ \\
\hline Dumping/gas bloat & - & - & 1 & 11 & - \\
\hline
\end{tabular}

period. One girl developed a subphrenic abscess which was drained percutaneously but led to a prolonged hospital stay. Median postoperative stay was 7 days (range 4-47).

Histopathological examination of the myenteric plexus in the excised muscle strip revealed absent ganglion cells in six patients and reduced numbers in four; in two of the latter there was evidence of ganglion cell degeneration.

\section{Discussion}

The overall incidence of achalasia is estimated at $0.5-1$ per 100000 with less than $5 \%$ of cases presenting in childhood..$^{10}$ The aetiology of the condition is unknown, but there appears to be a selective impairment of the non-adrenergic, noncholinergic inhibitory nerves near the lower oesophageal sphincter. ${ }^{112}$ Ganglion cells were absent from the myenteric plexus in six of 10 of our patients. Others have reported a total absence of ganglion cells in the distal oesophagus in more than $90 \%$ of patients with achalasia and denervation of the proximal stomach in half. ${ }^{13}$

The age at onset and the duration of symptoms before treatment in our cases compares well with other series of childhood achalasia. ${ }^{3+1014}$ Despite relatively severe respiratory symptoms and growth impairment in children with achalasia, there continues to be a significant delay in diagnosis and treatment. The condition may be misdiagnosed as asthma, underlining the complex clinical interaction between respiratory disorders and oesophageal dysmotility, ${ }^{15}$ or as anorexia nervosa, as noted by others. ${ }^{+16}$ Dysphagia, vomiting, and weight loss may be prominent symptoms in both anorexia nervosa and achalasia and a carefully performed barium swallow is essential to distinguish the two conditions in young girls.

Treatment for achalasia is directed towards reducing lower oesophageal sphincter pressure. Drugs such as nitrates or calcium antagonists, particularly nifedipine, cause a significant fall in sphincter pressure and may produce immediate relief of symptoms. However, the effect is most often short lived and rarely avoids the need for surgery. ${ }^{17} 18$

The results of forceful pneumatic dilatation in children are less impressive than in adults. ${ }^{19}$ The most encouraging reports have been in older children, most of whom have needed several dilatations, and a significant number subsequently required surgery for persistent symptoms. ${ }^{510}$ Pneumatic dilatations were of limited success in our patients, a finding in agreement with other paediatric series. ${ }^{3+10}$ Bougienage has almost no value in the initial treatment of achalasia. ${ }^{510}$ After myotomy alone, the long term incidence of gastro-oesophageal reflux is between 15 and 50\%; it increases with time and is greater after an 'extended' myotomy than after a 'limited' myotomy. ${ }^{3461420} \mathrm{We}$ and others have previously recommended a long myotomy on to the gastric fundus to prevent dysphagia together with an antireflux procedure. ${ }^{3-621}$ Our current results appear to validate this surgical approach; relief of dysphagia and respiratory problems in all children and no persistent obstructive symptoms from the wrap. Residual/recurrent pain 
responded to oesophageal balloon dilatation in two children but proved the most difficult symptom to treat. Severe persistent oesophageal pain may rarely necessitate oesophageal replacement as in one of our patients. ${ }^{22}$

1 Vantrappen G, Hellemans J. Treatment of achalasia and related motor disorders. Gastroenterology 1980; 79: 144-54.

Bello C, Castell DO. Esophageal motility disorders. Current Opinion in Gastroenterology 1991; 7: 539-44.

3 Vane DW, Cosby K, West K, Grosfeld JL. Late results following esophagomyotomy in children with achalasia. f Pediatr Surg 1988; 23: 515-9.

4 Nihoul-Fekete C, Bawab F, Lortat-Jacob S, Arhan P, Pellerin $D$. Achalasia of the esophagus in childhood: surgical D. Achalasia of the esophagus in childhood: surgical
treatment in 35 cases with special reference to familial cases treatment in 35 cases with special reference to familial cases
and glucocorticoid deficiency association. $\mathcal{F}$ Pediatr Surg and glucocorticoid

5 Nakayama DK, Shorter NA, Boyle JT, Watkins JB, O'Neill JA Jr. Pneumatic dilatation and operative treatment of achalasia in children. $\mathcal{F}$ Pediatr Surg 1987; 22: 619-22.

6 Buick RG, Spitz L. Achalasia of the cardia in children. Brf Surg 1985; 72: 341-3.

7 Allgrove J, Clayden GS, Grant DB, Macaulay JC. Familia glucocorticoid deficiency with achalasia of the cardia and deficient tear production. Lancet 1978; i: 1284-6.

8 Spitz L. Gastric transposition for esophageal substitution in children. $\mathcal{F}$ Pediatr Surg 1992; 27: 252-9.

9 Ellis FH Jr, Olsen Am. Achalasia of the esophagus. In: Dunphy JE, ed. Major problems in clinical surgery. Vol IX. Philadelphia: WB Saunders, 1969: 65-104.

10 Azizkhan RG, Tapper D, Eraklis A. Achalasia in childhood: a 20-year experience. $\mathcal{F}$ Pediatr Surg 1980; $15: 452-6$.

11 Cohen S. Motor disorders of the esophagus. N Engl f Med 1979; 301: 184-92.
12 Tlottrup A, Forman A, Funch-Jensen P, Raundahl U, Andersson KE. Effects of postganglionic nerve stimulation in esophageal achalasia: an in vitro study. Gut 1990; 31: 1720.

13 Csendes A, Smok G, Braghetto I, et al. Histological studies of Auerbach's plexuses of the oesophagus, stomach, jejunum and colon in patients with achalasia of the oesophagus correlation with gastric acid secretion, presence of parieta cells and gastric emptying of solids. Gut 1992; 33: 150-4.

14 Ballantine TVN, Fitzgerald JF, Grosfeld JL. Transabdominal esophagomyotomy for achalasia in children. $\mathcal{F}$ Pediatr Surg 1980; 15: 457-61.

15 Gustafsson PM, Kjellman NIM, Tibbling L. Bronchia asthma and acid reflux into the distal and proxima oesophagus. Arch Dis Child .1990; 65: 1255-8.

16 Duane PD, Magee TM, Alexander MS, Heatley RV, Losowsky MS. Oesophageal achalasia in adolescent women mistaken for anorexia nervosa. BMF 1992; 305: 43.

17 Maksimak M, Perlmutter DH, Winter HS. The use of nifedipine for the treatment of achalasia in children. nifedipine for the treatment of achalasia
$\mathcal{F}$ Pediatr Gastroenterol Nutr $1986 ; 5: 883-6$.

18 Smith H, Buick R, Booth I, Campbell C. The use of nifedipine for treatment of achalasia in children. $\mathcal{F}$ Pediatr Gastroenterol Nutr 1988; 7: 146.

19 Stark GA, Castell DO, Richter JE, Wu WC. Prospective randomized comparison of Brown-McKardy and microvasive balloon dilators in treatment of achalasia. $A m \mathcal{F}$ Gastroenterol 1990; 85: 1322-6.

20 Ellis FH Jr, Crozier RE, Watkins E Jr. Operation for esophageal achalasia. Results of esophagomyotomy without an antireflux operation. $\mathcal{F}$ Thorac Cardiovasc Surg 1984; 88: an antire

21 Tomlinson $P$, Grant AF. A review of 74 patients with oesophageal achalasia: the results of Heller's cardiooesophageal achalasia: the results of Heller's cardio-
myotomy, with and without Nissen fundoplication. Aust $N$ myotomy, with and without
$Z \mathcal{F}$ Surg $1981 ; 51: 48-51$.

22 Orringer MB, Stirling MC. Esophageal resection for achalasia: indications and results. Ann Thorac Surg 1989; 47: 340-5. 